\title{
Natural organic matter - the relationship between character and treatability
}

\author{
Simon A. Parsons, Bruce Jefferson, Emma H. Goslan, Peter R. Jarvis and David A. Fearing \\ School of Water Sciences, Cranfield University, Cranfield MK43 OAL, UK
}

\begin{abstract}
The characterisation and treatment of natural organic matter are becoming more important to the water utilities in the UK and around the world. This paper looks at the relationship between bulk and fractionated organic material and the performance of conventional water treatment processes.
\end{abstract}

Keywords Natural organic matter; characterisation; treatability

\section{Introduction}

Natural organic matter (NOM) is a mixture of organic compounds that occurs universally in ground and surface waters. NOM can cause major problems as it is converted into disinfection by-products (DBPs) when chlorine is used during water treatment (Krasner et al., 1989). These by-products can take the form of trihalomethanes (THMs), haloacetic acids (HAAs) and a host of other halogenated DBPs, a number of which have been shown to cause cancer in laboratory animals (Singer, 1999; Rodriguez et al., 2000). Recent legislation has reduced the THM standard in the US from 100 to $80 \mu \mathrm{g} \mathrm{L}^{-1}$ (Lin et al., 1999). A similar standard of $100 \mu \mathrm{g} \mathrm{L}^{-1}$ is in force in the UK and the European Commission has proposed standards for chloroform $\left(40 \mu \mathrm{g} \mathrm{L}^{-1}\right)$ and bromodichloromethane $\left(15 \mu \mathrm{g} \mathrm{L}^{-1}\right)$, (Drinking Water Inspectorate UK, 1998).

NOM found in water consists of both hydrophobic and hydrophilic components where the largest fraction is generally hydrophobic acids, which makes up approximately $50 \%$ of the dissolved organic carbon (DOC), (Thurman, 1985; Owen et al., 1993). These can be described as the aquatic acids or humic substances comprising of humic and fulvic acids. The humic substances are generally regarded as the main cause of natural colour and THM formation potential (THM-FP). For example for one water it has been reported that the hydrophobic fraction produced $51 \mu \mathrm{g} \mathrm{THM} \mathrm{mg}^{-1}$ DOC when compared to $21 \mu \mathrm{g} \mathrm{THM} \mathrm{mg}^{-1}$ DOC for the hydrophilic acid fraction (Krasner et al., 1996). The reactivity of individual fractions has also been reported with values for the humic and fulvic acid fractions of 46 and $27 \mu \mathrm{g}$ THM mg ${ }^{-1}$ DOC respectively, compared to a reactivity of $27 \mu \mathrm{g} \mathrm{THM} \mathrm{mg}^{-1}$ DOC for the hydrophilic fraction (Croué et al., 1993). Hydrophilic material has also been shown to be a cause for concern with regards to its THM-FP and it has been reported that $65 \%$ of the TOC and $56 \%$ of the THM-FP from the Colorado River was contributed by hydrophilic compounds (Owen et al., 1993). They showed that the hydrophilic fractions were exerting the largest chlorine demand when compared to the hydrophobic material (2.4 $\mathrm{mg} \mathrm{Cl}_{2} \mathrm{mg}^{-1}$ hydrophilic vs. $0.32 \mathrm{mg} \mathrm{Cl}_{2} \mathrm{mg}^{-1}$ hydrophobic), leading to greater THM formation.

The treatment of water has traditionally focused on the removal of either colour or turbidity, however recently some water treatment facilities have started to optimise their works purely on the removal of natural organic matter (Chow et al., 2000). To improve the performance of NOM removal it is key to firstly identify its character, as the type of organics will affect not only the choice of treatment process but also the performance of the selected 
process. This paper will look at the impact NOM character has on treatment process performance.

\section{Materials and methods}

\section{Fractionation}

Raw inlet water $(75 \mathrm{~L})$ and treated water collected after primary filtration $(300 \mathrm{~L})$ was passed through a Whatman $1 \mu \mathrm{m}$ pre-filter capsule and a Whatman $0.45 \mu \mathrm{m}$ filter capsule and acidified to $\mathrm{pH} 2$ using $\mathrm{HCl}$. All of the acidified filtered water was put through the XAD7HP/XAD-4 column pair (resin volume was $1,200 \mathrm{~mL}$ in each column). The effluent from both columns contained the non-acid hydrophilic fraction (HPI-NA). The XAD-8 column was back eluted with $\mathrm{NaOH}(0.1 \mathrm{M}, 1,800 \mathrm{~mL})$. The eluate was acidified to $\mathrm{pH} 2$ and passed through a $60 \mathrm{~mL}$ XAD-8 column. This was the hydrophobic acid fraction (HPO-A). The XAD-4 column was back eluted with $\mathrm{NaOH}(0.1 \mathrm{M}, 1,800 \mathrm{~mL})$. The eluate was acidified to pH 2 and passed through a $60 \mathrm{~mL}$ XAD-4 column. This was the hydrophilic acid fraction (HPI-A). The $\mathrm{pH}$ of the HPO-A was adjusted to 1 by adding concentrated $\mathrm{HCl}$, and left to settle for 24 hours and centrifuged. The supernatant (fulvic acid fraction - FAF) was decanted. The residual (humic acid fraction - HAF) was dissolved in the minimum required volume of $\mathrm{NaOH}(0.1 \mathrm{M}, \sim 50 \mathrm{~mL})$. The $\mathrm{HAF}$ was hydrogen saturated by passing it through a $5 \mathrm{~mL}$ column of Bio-Rad AG-MP-50 resin and rinsed with RO water $(5 \mathrm{~mL})$. The FAF was concentrated on a $20 \mathrm{~mL}$ column of XAD-8 and rinsed with RO water $(20 \mathrm{~mL})$ and desorbed with $\mathrm{NaOH}(0.1 \mathrm{M}, 50 \mathrm{~mL})$. The eluate was passed through a $5 \mathrm{~mL}$ column of Bio-Rad AGMP-50 resin and rinsed with RO water $(5 \mathrm{~mL})$. The HPI-A was pumped through a $20 \mathrm{~mL}$ column of XAD-4 resin and rinsed with $\mathrm{RO}$ water $(20 \mathrm{~mL})$ and desorbed with $\mathrm{NaOH}(0.1 \mathrm{M}$, $50 \mathrm{~mL}$ ). The eluate was pumped through a $5 \mathrm{~mL}$ column of Bio-Rad AG-MP-50 resin and rinsed with $\mathrm{RO}$ water $(5 \mathrm{~mL})$.

\section{Analytical techniques}

The samples were analysed for DOC and THMFP using the following methods. DOC $(\mathrm{mg} / \mathrm{L})$ was measured using a Shimadzu TOC-5000A, UV-Abs (1/m) was measured using a Jenway $6505 \mathrm{UV} / \mathrm{Vis}$ spectrophotometer, SUVA (L/mg.m) was calculated as a ratio of the UV-Abs to DOC and THM-FP was carried out using a method adapted from procedure 5710 in Standard Methods for the Treatment and Examination of Water and Wastewater (American Public Health Association, 1992). The method involved buffering samples at pH 7, chlorinating samples with excess free chlorine and storing the sample at $20^{\circ} \mathrm{C}$ for 7 days to allow

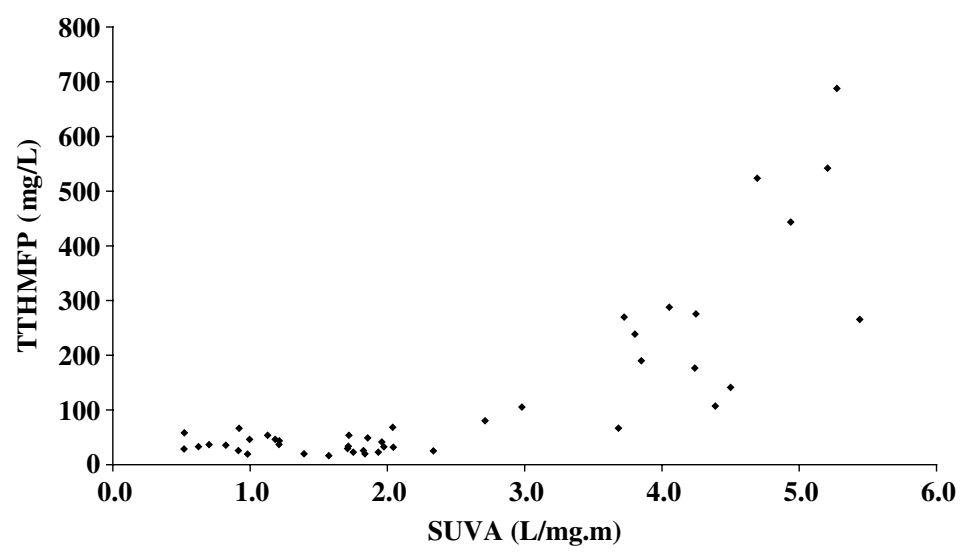



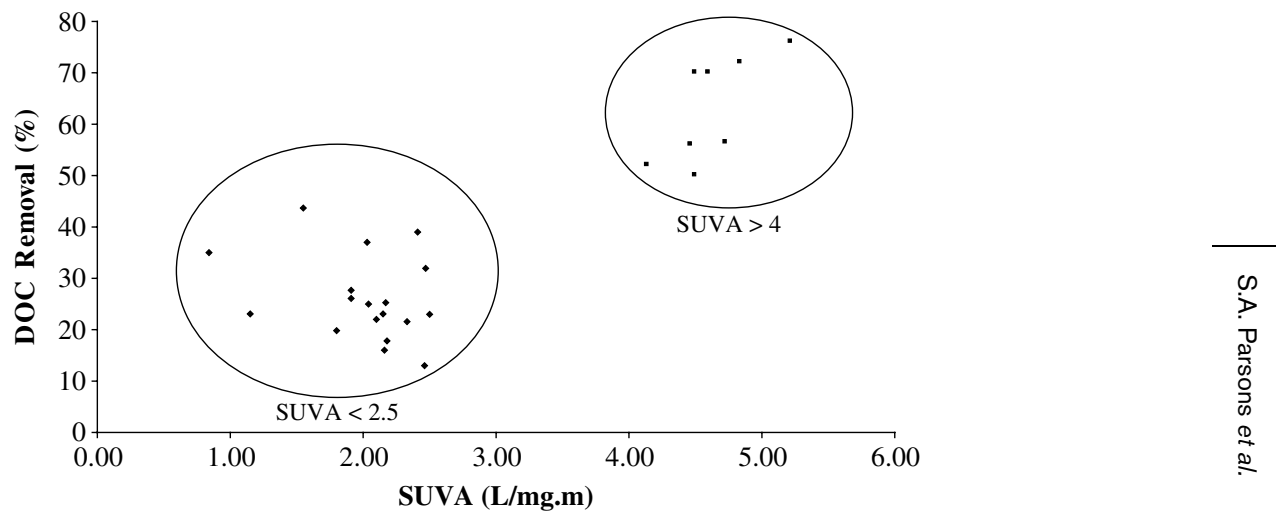

Figure 2 Relationship between SUVA and DOC focussing on hydrophobic and hydrophilic fractions. (Data taken from Croué et al., 1993; Owen et al., 1993; Edzwald, 1993; Crozes et al., 1995; Chow et al., 1999; Volk et al., 2000; Bell-Ajy et al., 2000)

the reaction to approach completion. The total THM (chloroform, dichlorobromoform, dibromochloroform and bromoform) concentration was measured using a SRI 9300A gas chromatograph.

\section{Results and discussion}

NOM can be characterised by bulk water parameters such as DOC, UV254, SUVA or can be fractionated into either charge or size fractions. Here we will look at what information on treatability we can gain from the analysis of bulk and fractionated organic material.

\section{Bulk organic material}

To investigate correlations between treatability, reactivity and organic character data from a number of raw and treated waters has been correlated. One parameter that has shown significant promise as an indicator of NOM character is SUVA. SUVA (specific UV absorbance), is defined as the UV absorbance of a given sample determined at $254 \mathrm{~nm}$ and divided by the DOC concentration of the solution, expressed in $\mathrm{m}^{-1} \mathrm{~L} / \mathrm{mg} \mathrm{C}$ and can be used to describe the composition of the water in terms of hydrophobicity and hydrophilicity,

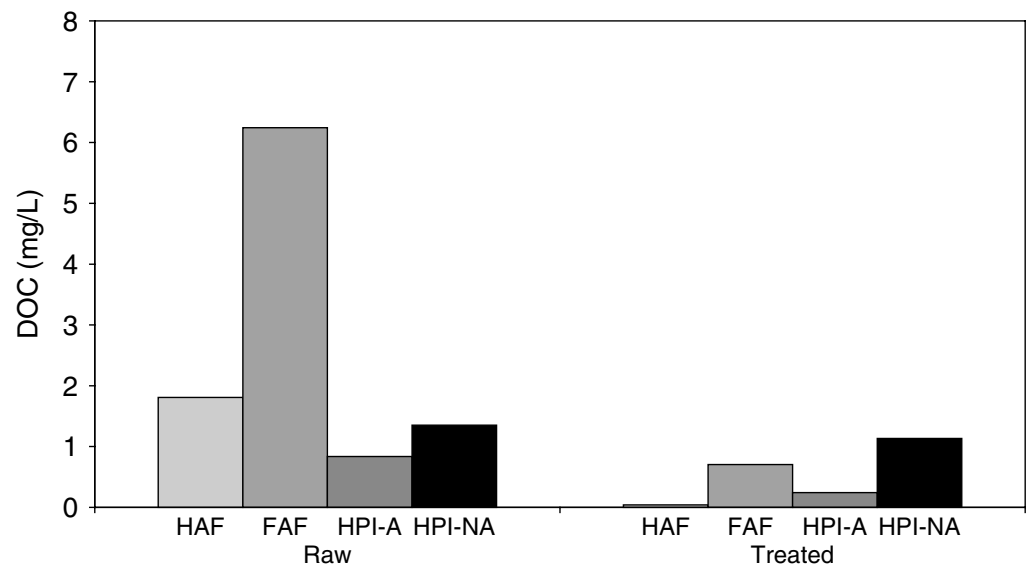

Figure 3 Isolated fraction DOC distribution of raw and treated water 


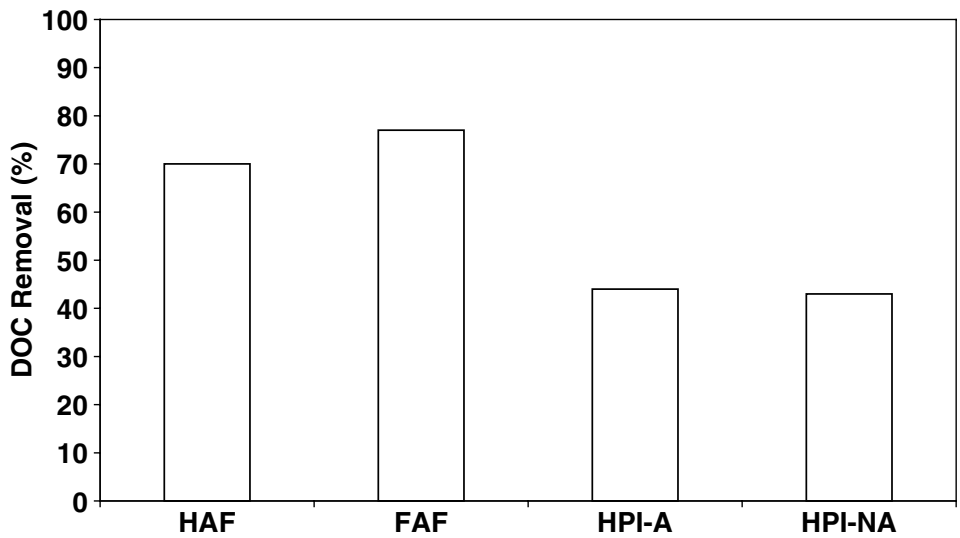

Figure 4 Optimum removal of individual NOM fractions with ferric sulphate coagulant (Fearing et al., 2002)

where a SUVA $>4$ indicates mainly hydrophobic and especially aromatic material whilst a SUVA $<3$ mainly hydrophilic material (Edzwald and Tobiason, 1999).

Here a relationship was identified between SUVA and THMFP (Figure 1) where once SUVA is above 4 (i.e. mainly hydrophobic organics) there is a strong correlation between the two parameters - the higher the SUVA the higher the THMFP. For water with SUVA below 3 no relationship exists between SUVA and THMFP except to say that it is never higher than $100 \mu \mathrm{g} / \mathrm{L}$. It is clear that the type of organic matter plays a major role in the effectiveness of process such as coagulation/flocculation. The impact of raw water SUVA on the performance of the coagulation process is shown in Figure 2 and whilst there is not a great correlation between SUVA and removal it is clear that the higher the SUVA the better the removal of DOC.

\section{Fractionationed organic material}

The fractionation of bulk organic matter (on XAD4 and XAD8 resins) in to hydrophilic and hydrophilic fractions is well known and widely used as a method to characterise NOM. The fractionation allows us to further understand the type of organic material found in a raw water source and hence gives us a better understanding of how well treatment processes deal with a

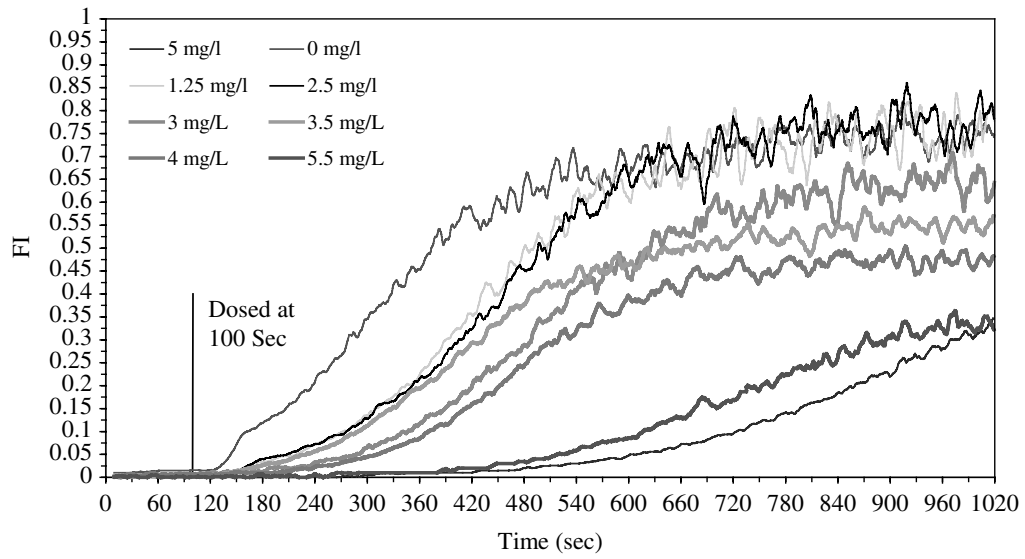

Figure 5 Effect of increasing concentrations of organic matter on the flocculation of kaolin with 
variety of organics. Data from the fractionation of an upland water source is shown below (Figure 3). It can be seen that the principal raw water fraction in terms of DOC and reactivity is the fulvic acid fraction (FAF) $(6.24 \mathrm{mg} / \mathrm{L}$; THMFP $1164.2 \mu \mathrm{g} / \mathrm{L}$ respectively) followed by the humic acid fraction (HAF) $(1.81 \mathrm{mg} / \mathrm{L}$; THMFP $215.1 \mu \mathrm{g} / \mathrm{L}$ respectively). In addition the results shows the removals achieved by coagulation for the DOC for each of the individual organic fractions. The current treatment conditions employed at this WTW as able to achieve high removals of DOC for HAF, FAF and HPI-A (98, 89 and 71\% respectively), whilst the THM-FP removal for those fractions is equally high (97, 94 and $93 \%$ respectively). However the treatment of the hydrophilic non-acids (HPI-NA) is poor with only $16 \%$ of the DOC and $31 \%$ of the THM-FP being removed by treatment.

To investigate the effect each fraction has on treatment each individual fraction was coagulated with ferric sulphate (Figure 4). HAF and FAF are fairly easily removed whilst even under optimised conditions the hydrophilic fractions are poorly removed. Further analysis of the results with high pressure size exclusion chromatography (HPSEC) showed that whilst large humic and fulvic molecules are easily removed the removal of small (>3,000 Daltons) is poor.

The organic material also effects the formation and strength of water treatment flocs. In the UK we have seasonal periods of elevated DOC (linked with rainfall) that lead to significant problems with treatment processes such as coagulation/flocculation, sedimentation, flotation and filtration. Reduced performance in any of these treatment stages leads to problems meeting quality standards and the remediation of these problems can be costly and often difficult to achieve with current process options. It is known that the efficacy of both coagulation and subsequent solid liquid separation processes for the removal of NOM is highly dependent upon the characteristics of the flocs formed and recent evidence has shown how certain organic fractions can significantly affect the growth and structure of flocs (Figure 5). Here it is clear that as the concentration of organic material increases then the rate of flocculation decreases as does the final floc size.

\section{Conclusions}

- Generally waters with a high SUVA will be more reactive with chlorine than those that have a low SUVA. It is also clear that generally these high SUVA waters are easier to treat by conventional treatment.

- The fractionation of bulk organic matter gives valuable information on the character and hence treatability of the water. It must be noted though that the fractionation is a snapshot of one period through the year and the type and reactivity of the fractions will change significantly from season to season.

- Conventional and membrane treatment processes are excellent at removing hydrophobic organic material whilst removal of hydrophilic material of small organic molecules is poor.

- Organic material also affects the nature of floc formed during treatment, often leading to weaker smaller flocs.

- The nature of organic plays a key role in the performance of treatment processes it is therefore important not only to consider bulk parameters such as DOC or colour when treating a water source.

\section{References}

Bell-Ajy, K., Abbaszadegan, M., Ibrahim, E., Verges, D. and LeChevallier, M. (2000). Conventional and Optimized Coagulation for NOM Removal. Journal of the American Water Works Association, 92(10), 44-58. 
Chow, C., van Leeuwen, J., Fabris, R., King, S., Withers, N., Spark, K. and Drikas, M. (2000). Enhanced Coagulation for Removal of Dissolved Organic Carbon with Alum - A Fractionation Approach. Sydney, Australia.

Chow, C.K.C., van Leeuwen, J.A., Drikas, M., Fabris, R., Spark, K.M. and Page, D.W. (1999). The Impact of the Character of Natural Organic Matter in Conventional Treatment with Alum. Water Science and Technology, 40(9), 97-104.

Croué, J.-P., Lefebvre, E., Martin, B. and Legube, B. (1993). Removal of Dissolved Hydrophobic and Hydrophilic Organic Substances During Coagulation/Flocculation of Surface Waters. Water Science and Technology, 27(11), 143-152.

Crozes, G., White, P. and Marshall, M. (1995). Enhanced Coagulation: its effect on NOM removal and chemical costs. Journal of the American Water Works Association, 87(1), 78-89.

Edzwald, J.K. (1993). Coagulation in Drinking Water Treatment: Particles, Organics and Coagulants. Water Science and Technology, 27(11), 21-35.

Edzwald, J.K. and Tobiason, J.E. (1999). Enhanced Coagulation: USA Requirements and a Broader View. Water, Science and Technology, 40(9), 63-70.

Fearing, D.A., Goslan, E.H., Banks, J., Wilson, D., Hillis, P., Campbell, A.T. and Parsons, S.A. (2002). Staged Coagulation for the Treatment of Refractory Organics. Journal of Environmental Engineering, (submitted).

Goslan, E.H., Fearing, D.A., Banks, J., Wilson, D., Hillis, P., Campbell, A.T. and Parsons, S.A. (2002). Seasonal Variations in the Disinfection By-Product Precursor Profile of a Reservoir Water. Journal of Water Supply: Research and Technology - AQUA, 51, 475-482.

Krasner, S.W., Croué, J.-P., Buffle, J. and Perdue, E.M. (1996). Three Approaches for Characterizing NOM. Journal of the American Water Works Association, 88(6), 66-79.

Krasner, S.W., McGuire, M.J., Jacangelo, J.G., Patania, N.L., Reagan, K.M. and Aieta, E.M. (1989). The Occurrence of Disinfection By-Products in US Drinking Water. Journal of the American Water Works Association, 81(8), 41-53.

Lin, C.-F., Huang, Y.-J. and Hao, O.J. (1999). Ultrafiltration Processes for Removing Humic Substances: Effect of Molecular Weight Fractions and PAC Treatment. Water Research, 33(5), 1252-1264.

New Drinking Water Regulations in the UK (1998). Drinking Water Inspectorate, UK.

Owen, D.M., Amy, G.L. and Chowdhury, Z.K. (1993). Characterization of Natural Organic Matter and Its Relationship to Treatability. Denver, CO, USA. AWWARF.

Rodriguez, M.J., Sérodes, J. and Morin, M. (2000). Estimation of Water Utility Compliance with Trihalomethane Regulations using a Modelling Approach. Journal of Water Supply: Research and Technology, 49(2), 57-73.

Singer, P.C. (1999). Humic Substances as Precursors for Potentially Harmful Disinfection By-Products. Water, Science and Technology, 40(9), 25-30.

Standard Methods for the Examination of Water and Wastewater (1992). 18th edition, American Public Health Association/American Water Works Association/Water Environment Federation, Washington, DC, USA.

Thurman, E.M. (1985). Humic Substances in Groundwater. In: Aiken, G.R., McKnight, D.M., Wershaw, R.L. and MacCarthy, P. (eds), pp. 87-103. John Wiley and Sons, New York.

Volk, C., Bell, K., Ibrahim, E., Verges, D., Amy, G. and Lechevallier, M. (2000). Impact of Enhanced and Optimised Coagulation on Removal of Organic Matter and its Biodegradable Fraction in Drinking Water. Water Research, 34(12), 3247-3257. 